\title{
A importância do uso habitacional nos programas nacionais de reabilitação de áreas urbanas antigas
}

\section{The importance of the habitation in the national programs of rehabilitation of ancient urbane areas}

\author{
Anna Cristina Andrade Ferreira ${ }^{1 *}$
}

\begin{abstract}
RESUMO
Quando falamos em projetos de reabilitação de áreas históricas podemos prever uma gama de usos que podem ser inseridos, mantidos ou restabelecidos nesses espaços, e dentre todos eles o que mais tem suscitado discussões é o uso habitacional. Este artigo busca discutir se o uso habitacional tem sido priorizado pelos programas nacionais de reabilitação urbana de áreas históricas, e se de fato pode-se verificar no Brasil a existência de uma política urbana efetiva para estas áreas, considerando todos os problemas envolvidos. A utilização do estoque construído dos centros antigos poderia auxiliar na diminuição do déficit habitacional, mas é preciso que os projetos se baseiem de fato na sustentabilidade continuada, e que a preocupação principal se desloque da exploração econômica para a recuperação socioeconômica das áreas antigas.
\end{abstract}

Palavras-chave: Habitação; Habitabilidade; Políticas Públicas; Reabilitação Urbana; Centros Históricos.

\section{ABSTRACT}

When we speak in projects of rehabilitation of historical areas we can predict a scale of uses that can be inserted, maintained or restored in these spaces, and among they what more has been causing discussions is the habitation. This article seeks to discuss if the housing use has been priorized in the national programs of urbane rehabilitation of historical areas, and if in fact it is possible to verify in Brazil the existence of an effective urban policy for these areas, considering all the problems involved. The use of the built stock of the ancient centers might help in the reduction of the housing deficit, but it is necessary that the projects are based in fact on the continued sustainability, and that concern shifts from economic exploitation to the socioeconomic recovery of the anciente areas.

Key words: Habitation; Habitability; Public Policies; Urbane Rehabilitation; Historical Centers.

\footnotetext{
${ }^{1}$ Universidade Federal Rural do Semi-Árido (UFERSA).

*E-mail: anna.cristina.a@gmail.com
} 


\section{INTRODUÇÃO}

Ao longo da história da preservação do patrimônio cultural várias ações foram implementadas com o intuito de salvaguardar bens imóveis e áreas urbanas importantes para a memória coletiva. Essa preocupação, na maioria das vezes, demonstra, ao menos no discurso que a embasa, possui um foco pedagógico, de transmissão de um conhecimento ancestral para as gerações futuras e, ao mesmo tempo, preservação da autenticidade e integridade dos lugares.

Porém, é possível se destacar, na definição dos objetivos das ações de preservação patrimonial, uma dificuldade enorme de equilíbrio no trato dos diversos valores envolvidos: de um lado os valores culturais, simbólicos, históricos, entre outros, que se refletem no trabalho de preservação dos bens, das feições urbanas e paisagísticas, dos valores imateriais e na busca por desacelerar, ou evitar, o processo de degradação; de outro o valor econômico representado pela exploração das áreas reabilitadas, seja pelo turismo, pelos interesses do mercado imobiliário ou pela manutenção e/ou retomada dos usos tradicionais. As ações voltadas aos centros históricos ${ }^{2}$ decadentes e esvaziados comumente visam tanto a melhoria da infraestrutura urbana como a reapropriação da área por parte da sociedade, aliando ações sazonais com a implementação do uso habitacional.

Documentos e cartas patrimoniais já preconizaram que a "morte prematura" de um bem pode ser diretamente associada a sua obsolescência, a ausência da função social, que necessariamente se entrelaça com a econômica. Existe uma gama de usos que podem ser estimulados, mantidos ou restabelecidos em uma área histórica, entre estes usos, destaca-se a atenção de grande parte das recomendações para com a relevância e destaque dado ao uso habitacional como essencial à retomada da função social destas áreas, além dos usos essenciais para sua manutenção, como serviços e comércios locais. Apesar disso, os resultados alcançados nessa direção são bastante perturbadores. Como aponta Nascimento (2011, p. 141):

Muitas vezes tensas, outras vezes ambíguas, e poucas vezes com sucesso, foram as experiências no campo da gestão do patrimônio cultural de uso e ocupação dos bens culturais urbanos com interesse social ou voltadas para atender à demanda por habitação nos mais diversos lugares de patrimônio no Brasil e no exterior.

Assim, a recuperação de imóveis para fins de habitação em áreas antigas degradadas é uma prática recomendada por documentos internacionais e observada nos projetos de reabilitação em diversas cidades do mundo, em alguns casos com o objetivo de manter uma população já

\footnotetext{
2 Utilizaremos neste artigo os termos "centro histórico" e "área histórica", como usualmente empregados, como sinônimo de "área de reconhecido valor patrimonial”, ou seja, áreas que já tenham sido identificadas por órgãos de preservação como detentoras de valor cultural e passível de ações preservacionistas.
} 
residente na área, em outros buscando atrair novos moradores. A segunda opção tem sido recorrente em centros abandonados ou ocupados por comunidades carentes. Em ambos os casos pode persistir um ônus do processo: o aumento do custo de vida impulsionado pelas melhorias de infraestrutura e inserção de novos equipamentos, como pontos comerciais e culturais, a criação ou requalificação de espaços públicos, e o aumento dos custos de moradia pode acabar por acarretar a expulsão, ou substituição, dos moradores e a mudança dos padrões sócio-econômicoculturais, processo este chamado de gentrificação (SMITH, 1996, p. 18; BIDOUZACHARIASEN, 2006, p. 22). ${ }^{3}$

O (NÃO) LUGAR DO USO HABITACIONAL NOS PROGRAMAS DE REABILITAÇÃO URBANA DE ÁREAS DE VALOR PATRIMONIAL NO BRASIL

O problema do déficit habitacional no Brasil vem se acentuando desde o final do século XIX, com o aumento da população nas áreas urbanas. Mas foi só a partir da década de 1930 que surgiram soluções, advindas do poder público, no sentido de tentar diminuir essa realidade, com a criação de programas voltados tanto para o financiamento habitacional quanto para a promoção de habitação de interesse social (HIS).

Segundo Raquel Rolnik (2010) a moradia adequada, bem localizada dentro da cidade, está longe de se tornar regra no Brasil, pois grande parte dos domicílios urbanos ainda se encontram em locais precários e em péssimas condições de habitabilidade. O problema parece residir nas políticas de planejamento e gestão urbana que, desconsiderando as diferentes demandas sociais e econômicas da população, beneficiam algumas áreas das cidades, fazendo com que haja uma setorização dos usos, a concentração dos empregos em poucas áreas, comumente distantes do local de moradia, além de uma grande demanda por deslocamentos, dentre outras questões.

O modelo de produção habitacional pelo poder público com redução dos custos por meio da aquisição de terras longínquas e baratas e produção em larga escala (construção de conjuntos em grandes lotes) contribuiu para o agravamento do processo de periferização. Este processo tem como resultado mediato a demanda de enormes investimentos não contabilizados inicialmente e potencializa problemas de deslocamentos e de vulnerabilidade social (ROLNIK, 2010, p. 12).

\footnotetext{
${ }^{3}$ Neil Smith (1996) explica o fenômeno de gentrificação situando-o no processo de desenvolvimento econômico desigual, considerando as diferentes escalas e as mudanças sociais que podem ocorrer nas cidades em determinados ciclos econômicos. Complementando o conceito Catherine Bidou-Zachariasen (2006) aponta que a gentrificação ocorre quando há a mudança do perfil socioeconômico e cultural dos usuários e moradores de uma determinada área, muitas vezes precedido pela expulsão de uma população existente.
} 
As políticas e programas nacionais, que tinham como objetivo prover a habitação, se focaram em garantir o maior número possível de moradias, sem considerar amplamente a necessidade de se garantir, também, condições de habitabilidade aos conjuntos edificados. Segundo Santos (1999, p. 9) a natureza urbana da questão habitacional precisa ser bem entendida "Esse assunto é central em qualquer estratégia de desenvolvimento urbano e a legislação que incide sobre questões tipicamente urbanas, como uso do solo, padrões de edificação etc., influenciam os mercados habitacionais locais e, portanto, as condições de habitabilidade da população". Assim, é preciso perceber o contexto em que essas ações foram implementadas, buscando entender suas diretrizes e os principais aspectos levados em consideração para combater o problema do déficit de moradia, considerando que este persiste até os dias atuais.

Outro ponto a ser questionado é o papel dos centros históricos nesse contexto. É sabido que muitas áreas antigas, no Brasil, concentram um vasto conjunto de edificações abandonadas ou subutilizadas, e que poderiam ser utilizadas como habitação. Um meio para que isso se concretize seria a ação articulada entre as políticas públicas voltadas para a promoção de habitação, que normalmente optam pela construção de novos conjuntos, e de reabilitação urbana, com direcionamento de investimentos para a recuperação e adequação dos edifícios existentes, além da criação de linhas de financiamento que facilitem o acesso da população.

Considerando que muitas políticas públicas e programas voltados para a habitação atuaram ao mesmo tempo em que alguns programas de reabilitação de áreas históricas (Tabela 01), o que se percebe é que, apesar de coexistirem, poucas vezes houve uma compatibilidade de objetivos entre esses programas, que permitisse o uso dos recursos em conjunto, fazendo com que houvesse, repetidamente, a necessidade da criação de outros programas e fundos complementares.

Tabela 01. Políticas e programas implementados no Brasil para provimento da habitação e reabilitação de áreas históricas.

\begin{tabular}{|c|c|c|c|}
\hline \multicolumn{2}{|c|}{$\begin{array}{c}\text { PROGRAMAS/POLÍTICAS DE } \\
\text { HABITAÇÃO }\end{array}$} & \multicolumn{2}{|c|}{$\begin{array}{c}\text { PROGRAMAS DE REABILITAÇÃO DE } \\
\text { ÁREAS CENTRAIS }\end{array}$} \\
\hline & & 1937 & $\begin{array}{lrr}\text { Criação do Serviço do } & \text { Patrimônio } \\
\text { Histórico e Artístico } & \text { Nacional } \\
\text { (SPHAN) - Atual IPHAN } & \end{array}$ \\
\hline 1942 & $\begin{array}{l}\text { Decreto-lei do Inquilinato, } \\
\text { Carteiras Prediais dos Institutos de } \\
\text { Aposentadoria e Previdência }\end{array}$ & & \\
\hline 1946 & Fundação Casa Popular (FCP) & & \\
\hline $\begin{array}{c}1964 \\
\text { (Governo } \\
\text { Militar) }\end{array}$ & $\begin{array}{llll}\text { Banco } & \text { Nacional de } & \text { Habitação } \\
\text { (BNH), } & \text { Companhia de } & \text { Habitação } \\
\text { Popular } & \text { (COHAB) } & \text { e } & \text { Serviço }\end{array}$ & & \\
\hline
\end{tabular}




\begin{tabular}{|c|c|c|c|}
\hline & $\begin{array}{l}\text { Federal de Habitação e Urbanismo } \\
\text { (SERFHAU) }\end{array}$ & & \\
\hline \multirow[t]{3}{*}{1972} & \multirow[t]{3}{*}{$\begin{array}{l}\text { Comunidade Urbana para } \\
\text { Recuperação Acelerada (CURA) }\end{array}$} & $1973-1976$ & $\begin{array}{l}\text { Programa Integrado de Reconstrução } \\
\text { de Cidades Históricas }(\mathrm{PCH})-\text { Fase } \\
\text { Nordeste }\end{array}$ \\
\hline & & $1977-1979$ & $\begin{array}{l}\text { Programa Integrado de Reconstrução } \\
\text { de Cidades Históricas }(\mathrm{PCH})-\text { Fase } \\
\text { Sudeste }\end{array}$ \\
\hline & & \multirow[t]{4}{*}{ 1979-1986 } & \multirow{4}{*}{$\begin{array}{l}\text { Programa Integrado de Reconstrução } \\
\text { de Cidades Históricas }(\mathrm{PCH})-\text { Fase de } \\
\text { Expansão } \\
\text { Programa de Recuperação e } \\
\text { Revitalização de Núcleos Históricos } \\
\text { (PRNH). }\end{array}$} \\
\hline $\begin{array}{c}1985 \\
\text { (Nova }\end{array}$ & \multirow[t]{2}{*}{$\begin{array}{l}\text { Criação do Ministério do } \\
\text { Desenvolvimento Urbano (MDU) }\end{array}$} & & \\
\hline República) & & & \\
\hline 1986 & $\begin{array}{l}\text { Extinção do BNH e incorporação } \\
\text { de sua agenda à Caixa Econômica } \\
\text { Federal (CEF) }\end{array}$ & & \\
\hline $\begin{array}{c}1995- \\
1998 \\
(\mathrm{FHC})\end{array}$ & Pró-Moradia e Habitar-Brasil & \multirow[t]{2}{*}{1995} & \multirow[t]{2}{*}{$\begin{array}{lcr}\text { Programas } & \text { Regionais } & \text { de } \\
\text { Desenvolvimento } & \text { do } & \text { Turismo } \\
\text { (PRODETUR) } & & \\
& & \end{array}$} \\
\hline 1999 & $\begin{array}{lcl}\text { Programa de } & \text { Arrendamento } \\
\text { Residencial (PAR) } & \end{array}$ & & \\
\hline 2000 & $\begin{array}{l}\text { Projeto Moradia, Estatuto das } \\
\text { Cidades }\end{array}$ & 2000 & $\begin{array}{l}\text { Monumenta/BID, Programa de } \\
\text { Revitalização de Sítios Históricos } \\
\text { (PRSH) (vinculado a CEF) e Programa } \\
\text { de Reabilitação Urbana de Sítios } \\
\text { Históricos (URBIS) }\end{array}$ \\
\hline \multirow[t]{2}{*}{2003} & \multirow[t]{2}{*}{$\begin{array}{l}\text { Criação do Ministério das Cidades, } \\
\text { Programa Nacional de Habitação } \\
\text { (PNH) }\end{array}$} & 2003 & 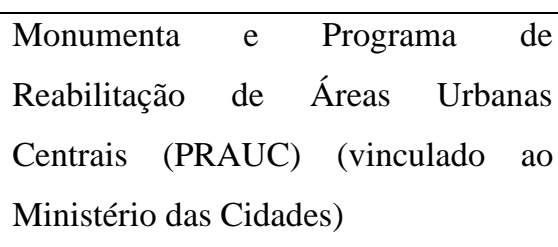 \\
\hline & & \multirow[t]{3}{*}{2004} & \multirow{3}{*}{$\begin{array}{l}\text { Subprograma de Financiamento par: } \\
\text { Recuperação de Imóveis Privado } \\
\text { (vinculado ao Monumenta) }\end{array}$} \\
\hline 2005 & $\begin{array}{l}\text { Sistema Nacional de Habitação de } \\
\text { Interesse Social (SNHIS) e Fundo } \\
\text { Nacional de Habitação }\end{array}$ & & \\
\hline 2007 & $\begin{array}{l}\text { Programa de Aceleração do } \\
\text { Crescimento (PAC) }\end{array}$ & & \\
\hline \multirow[t]{2}{*}{2009} & \multirow[t]{2}{*}{$\begin{array}{l}\text { Plano Nacional de Habitação } \\
\text { (PlanHab) e Programa Minha Casa } \\
\text { Minha Vida (PMCMV) }\end{array}$} & $2009-2012$ & $\begin{array}{l}\text { Programa de Aceleração do } \\
\text { Crescimento das Cidades Históricas } \\
\text { (PAC-CH) }\end{array}$ \\
\hline & & 2010 & \\
\hline
\end{tabular}




\begin{tabular}{l|l|l|l}
\hline 2012 & $\begin{array}{l}\text { PMCMV 2: Programa Nacional de } \\
\text { Habitação Urbana (PNHU) e } \\
\text { Programa Nacional de Habitação } \\
\text { Rural (PNHR) }\end{array}$ & & $\begin{array}{l}\text { Plano Nacional de Cultura (PNC): } \\
\text { Política Nacional de Patrimônio } \\
\text { Cultural (PNPC) e Sistema Nacional de } \\
\text { Patrimônio Cultural (SNPC) }\end{array}$ \\
\cline { 3 - 4 } & 2013 & $\begin{array}{l}\text { Programa de Aceleração do } \\
\text { Crescimento das Cidades Históricas } \\
\text { (PAC-CH) - Segunda Fase }\end{array}$ \\
\hline
\end{tabular}

Fonte: FERREIRA (2017, p. 43)

É importante ressaltar que a maioria dos programas e políticas habitacionais aqui citados atuava, principalmente, no financiamento dos projetos de habitação. Porém, com uma atuação limitada quanto a garantir uma localização adequada para implantação destes, pois essa escolha é uma responsabilidade dos municípios, por meio da elaboração de planos diretores e planos habitacionais. O que se vê, constantemente, é a implantação de HIS de acordo com os interesses do mercado imobiliário. As normativas municipais, responsáveis por zonear as áreas urbanas das cidades, ao invés de estimular a implantação de HIS em áreas consolidadas, garantindo uma ocupação democrática, sobretudo onde já se localizem os assentamentos, normalmente são as responsáveis por restringir a construção de novos empreendimentos às bordas de expansão durbana.

Aliado a isso, os órgãos de preservação cultural, muitas vezes focados em uma preservação museal mais preocupada em manter edificações antigas intactas, e vazias, ou com usos que possibilitem a exploração econômica e turística, desestimulam a inserção de moradores nos centros históricos, sobretudo quando se trata de uma população de menor renda, quando não causam a expulsão dos existentes.

É preciso reconhecer que houveram algumas tentativas dos programas e políticas habitacionais quanto a implementação de habitação em áreas antigas, buscando ocupar os imóveis subutilizado. Porém, nem sempre essas ações conseguiram alcançar seu objetivo, e dentre os motivos relacionados para isso configura a falta de articulação com os projetos de reabilitação de áreas históricas, causando, inclusive, a resistência dos órgãos de preservação em aprovar os projetos, e o pouco interesse da população nos financiamentos de imóveis antigos, que pode ser atribuído a burocracia na solicitação e às exigências de aprovação dos projetos.

No Brasil, assim como ocorrera na Europa, as ações de preservação do patrimônio histórico, durante muito tempo, deram prioridade aos monumentos isolados de destacado valor histórico e artístico. Essa visão pontual voltada para o monumento perdura aproximadamente até a década de 60/70, momento em que se observa como o crescimento das cidades e o surgimento de novas centralidades afeta a vitalidade dos centros históricos, fazendo com que alguns entrem em decadência e abandono. Assim, tem início a discussão de como poderiam ser implementadas 
ações de valorização econômica das cidades históricas, e, nos anos 70, surgiram no Brasil os primeiros projetos de reabilitação urbana que buscavam a adaptação do estoque construído, considerando tanto os conjuntos de reconhecido valor estético quanto às edificações mais modestas, visando em um primeiro momento a exploração turística, e posteriormente a retomada ou inserção do uso habitacional.

Desde esse primeiro momento observa-se a preocupação com a gentrificação dessas áreas, fato que incentiva a elaboração de Planos Diretores com diretrizes que visem frear a especulação imobiliária após a requalificação, e a criação de linhas investimento que facilitem aos usuários adquirir e/ou recuperar imóveis em áreas históricas. Segundo as reflexões de Zanchetti e Lapa (2002), sobre conservação integrada na preservação de cidades históricas, e Bidou-Zachariasen (2006), sobre o processo de gentrificação, há casos em que o objetivo é evitar que ela ocorra, buscando ações que ajudem a manter a população ocupante das áreas centrais, sobretudo as que caracterizam comunidades tradicionais. Em outros ela parece ser buscada como uma forma de "revitalização"4 das áreas, sobretudo aquelas que se apresentam degradadas e ocupadas por moradores de baixa renda.

Para Fernando Cárrion (2002, p. 48) um dos fatores mais relevantes para se intervir em áreas históricas é a definição do "sujeito patrimonial" (ou dos sujeitos), considerando os atores envolvidos e as motivações, o pertencimento econômico e cultural, "trata do direito à cidade, da dimensão social do patrimônio e do caráter público e coletivo dessa construção social”. Assim, embora as ações de reabilitação de centros históricos possuam motivações diversas, sejam de caráter econômico, cultural e social, nem sempre ficou claro para quem se deve a preservação, e qual a participação dos moradores, presents e futuros, nesse processo.

Assim, no início dos 1970 ocorre uma reorientação das políticas de preservação do patrimônio urbano, impulsionada pelo crescimento industrial no Sudeste, e pela descaracterização urbana de cidades históricas no Nordeste. Nesse momento o Instituto do Patrimônio Histórico e Artístico Nacional (IPHAN) buscou o apoio técnico e financeiro necessário junto a Unesco. Os estudos realizados a partir dai apontavam inevitavelmente para a necessidade de reestruturação do sistema estatal de proteção, e destacavam o valor econômico do patrimônio cultural. Assim, o turismo surgiu nos países subdesenvolvidos como a atividade econômica mais adequada ao aporte dessa valorização (SANT’ANNA, 2014, p. 214), muitas vezes suplantando o uso residencial, e até estimulando a expulsão de moradores, se seus aspectos sociais não se adequassem ao produto que se pretendia vender.

\footnotetext{
${ }^{4} \mathrm{O}$ termo "revitalização", comumente empregado especialmente em programas voltados prioritariamente para a exploração econômica de áreas de valor patrimonial, tem sido criticado entre os especialistas da área como um conceito que desconsidera a "vida" anterior destas áreas (cortiços, prostituição, ocupação por uma camada de baixa renda, etc).
} 
Foi dentro deste contexto que em 1973 foi criado o Programa Integrado de Reconstrução de Cidades Históricas - $\mathrm{PCH}$, que foi o primeiro criado para se discutir a relação entre o incremento econômico e o patrimônio cultural e a investir recursos na recuperação das áreas urbanas de interesse histórico.

Idealizado como um programa regional, oficialmente buscava a geração de renda para o Nordeste através do desdobramento da atividade turística e da conservação do patrimônio histórico com atividades integradas entre os governos federal, estadual e municipal. Como aponta Rafaela Corrêa (2014, p. 2), o principal objetivo era a preservação dos monumentos tombados a partir do seu uso, tornando-os economicamente viáveis, ou seja, criando uma "possibilidade de autossustentação econômica", onde inicialmente seriam implementadas ações com financiamento público, e depois a implementação do turismo geraria o financiamento necessário para a conservação dos monumentos.

O que chama a atenção nesse processo é que, embora se note a clara necessidade de apoio da comunidade para seu sucesso, ainda não se mencionava, nesse primeiro momento, a participação da população, segundo os preceitos da conservação integrada já utilizados no período em outros países. A criação do PCH teve uma boa aceitação frente a opinião pública, porém no campo preservacionista houveram duras críticas a ênfase dada ao uso turístico como principal modo de conservação, e à priorização de cidades que já possuíam uma infraestrutura turística, e não às que corriam mais riscos de perda do seu patrimônio cultural. É interessante observar que, embora o foco fosse a captação econômica através do turismo, já existia um debate quanto a necessidade da retomada do uso habitacional nessas áreas, como ressalta Marcia Sant'Anna (1995, p. 197) “desde o final dos anos 70, a habitação surgiu como a instância mais adequada e capaz de traduzir em ações concretas os princípios da política de preservação que se queria, aliada à promoção social e à valorização econômica do patrimônio".

O PCH funcionou exclusivamente no Nordeste até 1976, com 54 projetos aprovados, onde cerca de $90 \%$ eram obras de restauração e conservação de imóveis, em sua maioria destinados a serviços públicos ou ao uso turístico, não constam projetos para habitação ou comércio de caráter local, e poucos focados na recuperação urbanísticas das áreas (SANT'ANNA, 2014, p. 226). Apesar de ser considerado um período de relativo sucesso pelos órgãos de preservação, houveram muitas críticas quanto à excessiva exploração econômica dos bens. Canclini (2003, p. 196) ressalta a mudança de papel do patrimônio cultural brasileiro e sua relação com a sociedade, devido às novas relações de consumo estabelecidas.

Em 1977 o PCH foi expandido para o Sudeste, com mais recursos, porém, menos resultados. E em 1979 suas ações se ampliam para todo o território nacional, mas, em vez da implementação do turismo, o seu objetivo principal passa a ser o desenvolvimento urbano buscando a melhoria econômica das áreas históricas. Dentro dessas novas diretrizes houve uma 
tentativa de se criar um programa habitacional específico para sítios históricos através do Banco Nacional da Habitação - BNH.

$\mathrm{O}$ ponto de partida foi a aplicação de um projeto piloto na cidade de Olinda/PE, onde o IPHAN contribuía com recursos para financiamentos a fundo perdido, e aos beneficiários cabia o pagamento da parte financiada pelo BNH. Foi uma breve experiência, porém considerada um sucesso por ter conquistado o interesse e participação dos moradores, mas infelizmente o projeto foi encerrado em 1986, com a extinção do PCH e do BNH, sem que fosse implantado em outras cidades (MACHADO, in: DIOGO, 2009, p. 12).

Uma das consequências do PCH foi o aumento no número de tombamentos de áreas urbanas, impulsionados pela possibilidade de exploração turística e captação de recursos federais. Para dinamizar a preservação dessas áreas tombadas, em 1990 foi criado o Programa MONUMENTA/BID, cujas obras serão iniciadas efetivamente apenas em 2000, E se configurava como um plano de preservação urbana criado pelo Governo Federal e o Banco Interamericano de Desenvolvimento - BID, com a intenção era viabilizar um programa com ênfase nos sítios e conjuntos urbanos (DUARTE JUNIOR, 2010, p. 55).

Um dos seus objetivos era integrar desde a restauração de monumentos até a capacitação de mão-de-obra, além de incentivar o desenvolvimento local através do turismo. Mas ao contrário do $\mathrm{PCH}$, desde o início ocorre o envolvimento da sociedade civil (moradores, usuários, proprietários, empreendedores), através dos projetos de capacitação e promoção de atividades econômicas e da recuperação dos imóveis privados e de atividades de educação patrimonial.

Outro diferencial do programa foi o empenho empregado em realizar melhorias nos imóveis, sobretudo os que eram utilizados para fins de moradia, comércios e serviços locais, através de condições especiais de financiamento facilitado, buscando garantir a permanência da população nos centros históricos.

\footnotetext{
Para entender esse papel da moradia é importante lembrar que os processos de crescimento urbano geram em diversas cidades, em particular nas grandes, o esvaziamento e a degradação das áreas centrais, caracterizados principalmente pela redução do número de moradores, subutilização dos imóveis, deterioração do patrimônio histórico, precarização das moradias, concentração de atividades informais, mudança no perfil socioeconômico dos moradores, dos usuários e das atividades locais, além da transferência de organismos públicos e privados para outras localidades (DIOGO, 2009, p. 20).
}

Para os idealizadores do Monumenta era preciso reconhecer, e tentar solucionar, uma gama de problemas percebidos em ações anteriores de preservação patrimonial, como a falta, ou limitação, de recursos dos proprietários e governos locais, cidades descapitalizadas e sem infraestrutura, limitação do quadro técnico dos órgãos de preservação, escassez na manutenção dos imóveis, e o custo constante dos serviços de restauro e conservação (TADDEI NETO, 2001, p. 45). Esse era o discurso oficial, que se baseava na noção de sustentabilidade continuada. 
Em 2003 com a mudança do Governo Federal, ocorreram grandes alterações no programa. Sob essa perspectiva foi criado, em 2004, o subprograma de Financiamento para Recuperação de Imóveis Privados, em parceria com a Caixa Econômica, que oferecia recursos para recuperação de edificações sobre proteção federal e sua adaptação a diversos usos, inclusive habitacional, buscando resguardar a identidade cultural do bem. $O$ pedido de financiamento podia ser feito por pessoa física ou jurídica, sem juros, e em até quinze anos quando de uso habitacional ou misto, e dez anos para outros usos, "Este é considerado um dos pontos altos do Monumenta, por atingir um contingente populacional carente e sempre colocado à margem das benesses da preservação" (DUARTE JUNIOR, 2010, p. 76).

De modo geral, o Monumenta apresentou melhores resultados em cidades menores, que necessitavam de investimentos em infraestrutura, mas deixou a desejar em cidades maiores (REBOUÇAS, 2013, p. 8). Ao se comparar, por exemplo, as experiências da cidade de Cachoeira, no interior da Bahia, e do Bairro do Recife e Olinda, em Pernambuco, verifica-se que na primeira cidade alcançaram-se os objetivos do programa, com uma grande adesão da população e a realização de 35 contratos (selecionados de um universo de 141 proponentes), enquanto no Bairro do Recife apenas 17 proprietários aderiram ao edital e nenhuma proposta foi concretizada e, finalmente, em Olinda, de um número pequeno de proponentes (19), apenas 02 conseguem chegar ao contrato assinado (VIEIRA; OLIVEIRA; LIRA, 2011, p. 11).

Ainda na vigência do Monumenta $^{5}$, foi lançado o Programa de Aceleração do Crescimento das Cidades Históricas - PAC Cidades Históricas ${ }^{6}$, integrado à Política Nacional do Patrimônio Cultural. Uma das diretrizes apontadas era a de que para que hajam melhores resultados seria preciso garantir a participação constante da população, com realização de ações de educação patrimonial e audiências públicas. As ações poderiam englobar o financiamento de imóveis privados, requalificação urbana e melhorias na infraestrutura, recuperação e promoção do patrimônio cultural, fomento às cadeias produtivas locais e convênios com municípios, estados, ONGs e parcerias com empresas (BRASIL, 2009, p. 17).

Os cinco objetivos principais do PAC Cidades Históricas eram promover a requalificação urbanística dos sítios históricos e estimular usos que garantam seu desenvolvimento econômico, social e cultural; investir na infraestrutura urbana e social; ampliar o financiamento para a recuperação de imóveis privados; recuperar monumentos e imóveis públicos com destinação de

\footnotetext{
5 O Monumenta possuía como meta temporal, ser realizado até 2011. Funcionou como um programa estratégico do MinC até 2010, quando passou a fazer parte dos Programas do IPHAN. O Programa Monumenta foi essencial para o PAC Cidades Históricas, lançado em 2009, pois foi, em grande parte, a partir das experiências adquiridas em sua vigência que se pode formatar o novo programa (IPHAN, 2012, p. 71).

${ }^{6}$ O Programa de Recuperação de Imóveis Privados, iniciado no Monumenta, continua dentro do PAC Cidades Históricas, estabelecendo por meio de financiamentos viabilizados para todas as cidades históricas do Norte e Nordeste através de parceria firmada com o Banco do Nordeste (IPHAN, 2012, p. 23).
} 
uso de interesse social; fomentar o desenvolvimento das cadeias produtivas locais; promover o patrimônio cultural, o intercâmbio, a formação e a capacitação de agentes, técnicos e gestores (BRASIL, 2009, p. 21-23). Dentre as ações previstas para o alcance desses objetivos está o fomento às atividades culturais e a garantia de uso dos edifícios, a promoção da habitação de interesse social e ampliação do financiamento de imóveis privados, parcerias com universidades e reabilitação de áreas de convívio, além da implantação de uma rede técnica que possa auxiliar projetos futuros. Embora seja um programa bem abrangente, uma das principais críticas ao PAC Cidades Históricas é que a maioria de seus projetos não saem do papel.

Entre Monumenta/BID, Monumenta, PAC e PAC Cidades Históricas observamos que os princípios que os impulsionam são muito semelhantes e baseados, sobretudo, na noção de sustentabilidade continua. Porém, a suposta participação da população, que seria um aspecto importante para se alcançar essa sustentabilidade, sempre se apresenta como uma grande fragilidade, sobretudo quando se trata de uma população de baixa renda residente nas áreas histórias. O que se percebe, de fato, é que em todos os projetos citados foi dada uma importância muito maior à recuperação de áreas, visando a geração de um suporte econômico para as cidades, seja pelo comércio ou turismo, em detrimento de ações de implementação do uso habitacional.

\section{CONSIDERAÇÕES FINAIS}

O panorama da preservação do patrimônio cultural no Brasil mostra que, desde a década de 60, amplia-se o número de tombamentos que delimitam áreas históricas visando sua preservação. Porém, esse reconhecimento concedido através do tombamento, não garante uma manutenção adequada desse patrimônio e sua identidade. As ações implementadas nestas áreas de reconhecido valor patrimonial buscam sempre reverter um estado de decadência econômica já instalado e muitas vezes levam a transformações indesejadas no que se esperava preservar.

Ao analisar os três grandes programas de reabilitação de áreas urbanas de interesse histórico implementados no Brasil - PCH, Monumenta/BID e PAC Cidades Históricas -, podemos perceber que eles tinham como ponto em comum buscar ações de garantissem a reinserção das áreas de intervenção na dinâmica urbana da cidade, ao mesmo tempo que pudessem ocasionar a restruturação econômica da região, mas com poucas ações voltadas à manutenção ou reinserção do uso habitacional.

Em um primeiro momento, com o PCH, o exemplo europeu de utilização da exploração turística como elemento alavancador da reabilitação de áreas históricas decadentes é aplicado como a melhor solução, e o que se vê é uma enxurradas de pedidos de tombamentos de cidades visando a captação de recursos para implementação de melhorias e recuperação de imóveis antigos com foco nesse uso sazonal, e quase nenhuma articulação no sentido de aliar a preservação 
do patrimônio histórico e as políticas habitacionais. O resultado culmina na recuperação de poucos bens, e uma reabilitação momentânea e inconsistente, mas cujos problemas acabaram por gerar reflexões que auxiliaram as ações posteriores.

Com o Monumenta e o PAC já se pode observar considerações não só de cunho econômico, mas também socioculturais, com objetivos que incluíam a população no processo e a participação de investidores privados, com a criação de fundos de financiamento e alívios fiscais, ações que se enquadram nos preceitos da Conservação Integrada. A implementação do uso habitacional passou a ser o foco principal da recuperação das áreas históricas, buscando além da recuperação dos imóveis a retomada da identidade, do vínculo sociedade-patrimônio. Entretanto, os resultados ainda estão muito aquém do esperado.

Nos três períodos mencionados um problema parece persistir, a ausência de atuações complementares e articuladas das três esferas públicas, federal, estadual e municipal. Mesmo com a criação de órgãos estaduais e locais de preservação, e o estabelecimento de instrumentos legais de planejamento e de gestão, é fato que os estados carecem de planos e políticas culturais consistentes, que trabalhem de forma articulada e consigam configurar um sistema nacional de preservação.

Assim, parece ainda não ter sido encontrada uma maneira de equilibrar todos os valores identificados para uma área de reconhecido valor patrimonial. Nesta busca, percebe-se, por um lado, como é difícil usufruir da capacidade de exploração econômica destas áreas especialmente via turismo, sem transformá-las em cenários esvaziados que passam a fazer parte do conjunto de fotos oficiais de todos que visitam a cidade. Por outro lado, chama a atenção a insistência das recomendações internacionais acerca da importância da manutenção do uso habitacional para que se alcance a reabilitação sustentável dessas áreas, e os poucos resultados que podem se considerar exitosos nesse sentido no Brasil. Será o uso habitacional nas áreas de valor patrimonial, uma utopia? Como conseguir reforçar outras formas de ocupação que reforcem a possibilidade de apoio ao uso habitacional? Essa são algumas das questões que permanecem entre nossas inquietações.

\section{REFERÊNCIAS}

BIDOU-ZACHARIASEN, Catherine (org.). De volta à cidade: dos processos de gentrificação às políticas de "revitalização" dos centros urbanos. São Paulo: Annablume, 2006.

CANCLINI, Néstor García. Culturas Híbridas. 4. ed. São Paulo: Editora da Universidade de São Paulo, 2003.

CORRÊA, Sandra Rafaela Magalhães. Formulação e implementação do Programa de Cidades Históricas (PCH): 1972/1979. Rio de Janeiro: V Seminário Internacional - Políticas Culturais/Fundação Casa de Rui Barbosa, 7 a 9 de maio/2014. 
DIOGO, Érica (org.). Recuperação de imóveis privados em centros históricos. Brasília: IPHAN/Programa Monumenta, 2009.

DUARTE JUNIOR, Romeu. Programa Monumenta: uma experiência em preservação urbana no Brasil. São Paulo: Revista CPC, n. 10, p. 49-88, maio/out 2010.

FERREIRA, Anna Cristina Andrade. Casa sem pessoas para pessoas sem casa: a reabilitação de áreas históricas e o uso habitacional na realidade brasileira. João Pessoa:

PPGAU/UFRN, 2017. (Tese de Doutorado) Disponível em: https://repositorio.ufrn.br/handle/123456789/25057

IPHAN. Planos de Ação para Cidades Históricas Patrimônio Cultural e Desenvolvimento Social: Construindo o Sistema Nacional de Patrimônio Cultural. Brasília: IPHAN/ABCH, 2009.

. Financiamento para recuperação de imóveis privados. Rio de Janeiro: Acervo MONUMENTA/IPHAN, s/d. Disponível em:

http://portal.iphan.gov.br/uploads/ckfinder/arquivos/20_1\%20Olinda\%20e\%20Goiana\%E2\%80 $\% 93 \% 20 \mathrm{PE} \% 20$ assinam\%20conv\%C3\%AAnios\%20do\%20PAC $\% 20 \mathrm{Cidades} \% 20 \mathrm{Hist} \% \mathrm{C} 3 \% \mathrm{~B}$ 3ricas.pdf

PAC Cidades Históricas: Patrimônio, desenvolvimento e cidadania. Brasília: MinC/IPHAN, 2009. Disponível em: http://portal.iphan.gov.br/uploads/ckfinder/arquivos/Cidades\%20Hist\%C3\%B3ricas\%20$\% 20$ Noticias\%202\%202009.pdf

. PAC2. Brasília: MinC/IPHAN, 2014. Disponível em: http://portal.iphan.gov.br/uploads/ckfinder/arquivos/PAC_2_Cidades_Historicas.pdf

JOKILEHTO, Jukka. Considerations on Authenticity and Integrity in World Heritage Context. In: City \& Time 2 (1): 1. Disponível em: http://www.ct.ceci-br.org, 2006.

JOKILEHTO, Jukka. Authenticity: a General Framework for the Concept. In: LARSEN, Knut Einar (ed.). Nara Conference on Authenticity - Proceedings. Japan: UNESCO/ICCROM/ICOMOS, 1995. p. 17-34.

NASCIMENTO, Flávia Brito do. Blocos de memórias: habitação social, arquitetura moderna e patrimônio cultural. São Paulo: Tese/ FAU/ USP, 2011.

REBOUÇAS, Thais de Miranda. O Programa Monumenta em Salvador: do financiamento do projeto. In: Revista Brasileira de Estudos Urbanos e Regionais. Disponível em: http://unuhospedagem.com.br/revista/rbeur/index.php/anais/article/viewFile/4579/4448

ROLNIK, Raquel (org.). Como produzir moradia bem localizada com recursos do programa minha casa minha vida?: implementando os instrumentos do Estatuto da Cidade. Brasília: Ministério das Cidades, 2010. Disponível em: https://www.mprs.mp.br/areas/urbanistico/arquivos/manuais_orientacao/pmcmv.pdf.

SANT'ANNA, Márcia. Da cidade-monumento à cidade documento. A trajetória da norma de preservação de áreas urbanas no Brasil (1937-1990). Salvador:Dissert/PPGAU/UFBA, 1995.

. A cidade-atração: a norma de preservação de centros urbanos no Brasil dos anos 90 . Salvador: Tese/PPGAU/UFBA, 2004. 
Da cidade-monumento à cidade-documento: a norma de preservação de áreas urbanas no Brasil 1937-1990. Salvador: Oiti Editora, 2014.

SANTOS, Cláudio Hamilton M. Políticas Federais de Habitação no Brasil: 1964/1998. Texto para discussão $\mathrm{N}^{\circ}$ 654. Brasília: IPEA, julho de 1999. Disponível em:

http://repositorio.ipea.gov.br/bitstream/11058/2814/1/td_0654.pdf.

SMITH, Neil. Gentrification, the Frontier, and the Restructuring of Urban Space. In: Readings in Urban Theory edited by Susan S. Fainstein and Scott Campbell. Cambridge, Massachusetts: Blackwell Publishers, 1996.

TADDEI NETO, Pedro. Policies of historic and cultural heritage. in: Brazil. In: MARTINBROWN, Joan; SERAGELDIN, Ismail; SHLUGER, Ephim (Orgs.). Historic cities and sacred sites - cultural roots for urbanfutures. Washington: The International Bank for Reconstruction and Development/The World Bank, 2001. p. 41-45.

VIEIRA, Natália Miranda; OLIVEIRA, Terezinha Monteiro; LIRA, Karina Monteiro. Conservação e Preservação de Imóveis Privados: Novas Tentativas, Velhas Dificuldades. Natal: SAL- Seminário de Arquitetura Latino-Americana, 2011.

ZANCHETTI, Sílvio M.; LAPA, Tomás. Conservação integrada urbana e territorial. In: ZANCHETTI, Sílvio (org.). Gestão do patrimônio cultural integrado. Recife: EdUFPE, 2002. 